\title{
Laparoscopic repair for perforated peptic ulcer: our experience, a comparison with the open approach and a review of the literature.
}

Samuele Vaccari ${ }^{1}$ Vito D'Andrea ${ }^{1}$ Augusto Lauro ${ }^{2 *}$ Roberto d'Intino ${ }^{2}$ Eliana Gulotta ${ }^{1}$ Maurizio Cervellera ${ }^{2}$ Valeria Tonini ${ }^{2}$

${ }^{1}$ Department of Surgical Sciences, Umberto I University Hospital - La Sapienza - Rome, Italy

${ }^{2}$ Emergency Surgery, St. Orsola University Hospital, Alma Mater Studiorum, Bologna, Italy

\section{To Cite}

Vaccari S, D’Andrea V, Lauro A, D’Intino R, Gulotta E, Cervellara M, Tonini V. Laparoscopic repair for perforated peptic ulcer: our experience, a comparison with the open approach and a review of the literature. J Gastric Surg 2020; 2(2): 26-32

\section{Publication history}

Received: May 02, 2020

Accepted: May 10,2020

Article in press: May 11, 2020

Published on line: May 12, 2020

\section{*Correspondence to}

Dr. Augusto Lauro

Emergency Surgery

St. Orsola University Hospital

Alma Mater Studiorum

Via Giuseppe Massarenti, 9

40138 Bologna, Italy

augustola@yahoo.com

\section{ABSTRACT \\ Background:}

The incidence of perforated peptic ulcers has decreased during the last decades but the optimal treatment for these patients remains controversial. At the same time, a laparoscopic approach to this condition has been adopted by an increased number of surgeons.

Therefore, this study wants to evaluate the postoperative results of the laparoscopic treatment of perforated peptic ulcer performed in one Italian center with extensive experience in laparoscopic surgery.

\section{Methods:}

This retrospective study includes 94 patients who were operated for perforated peptic ulcer peritonitis at "St. Orsola Hospital - Emergency Surgery Unit - University of Bologna" from May 2014 to December 2019. The patients' charts were reviewed for demographics, surgical procedure, complications, and short-term outcomes.

\section{Results:}

The diagnosis was made clinically and confirmed by the presence of gas under diaphragm on abdominal X-ray. All patients underwent primary suture repair with or without omentopexy. Boey score 0 or 1 was found in $66(70 \%)$ patients, Boey 2 or 3 in $28(30 \%)$ patients. The operative time was between 35 and 255 minutes, with a mean of 93 minutes. The overall median hospital stay was 9.5 (1-60) days. Post-operative complications occurred in $19(20 \%)$ patients and 18 (19\%) patients died.

\section{Conclusions:}

Perforated peptic ulcer is a severe condition that requires early hospital admission and immediate surgery. Laparoscopy in experienced centers and for selected patients is safe, associated with optimal outcomes and should be the preferred approach.

\section{Keywords:}

peptic ulcer, gastric perforation, peritonitis, laparoscopy, minimally invasive surgery, emergency surgery. 


\section{Background:}

Treatment outcomes for peptic ulcer disease (PUD) have been substantially improved over the past few decades, first of all in the 1970s with the introduction of H2-blockers followed by proton pump inhibitors in the 1980s and the introduction of antibacterial therapy to eradicate Helicobacter pylori, leading to a decrease in elective surgical procedures for this disease[1].

However, there are discordant results in the literature, while the Scandinavian groups[2,3] reported a reduced incidence of perforated peptic ulcer due to these treatments, several studies reported no change or even an increase in the incidence of perforated peptic ulcer[4, 5].

Improved medical management of PUD has virtually eradicated the need for acid-reducing surgery, such as proximal selective vagotomy, gastric resection and surgery performed for benign gastric outlet obstruction[6, 7].

However gastric or duodenal perforation remains a life threatening complication of PUD; it is one of the commonest causes of emergency hospitalization and surgery in PUD and develops in $2-14 \%$ of patients $[8,9]$. Most authors consider perforated gastric and duodenal ulcer as a single disease entity. However, Hodnett et al.[10] reported that perforated gastric ulcer has a higher morbidity and mortality than perforated duodenal ulcer. Moreover, perforated gastric ulcer is more commonly associated with older patients, larger ulcer size, and more severe intraperitoneal contamination than duodenal one[11, 12].

Although predominantly benign nature of peptic ulcer, underlying gastric cancer can occasionally present with perforation, as reported in over $13 \%$ of patients in one series[13].

The incidence of perforated peptic ulcer is approximately 7-10 per 10.000 population per year[5, 14]. An estimated $2 \%$ to $10 \%$ of patients with PUD will present with perforation of the stomach or the duodenum in their lifetimes, with a high risk for mortality in the elderly[15, 16]. Acute perforations of the duodenum are estimated to occur in $2-10 \%$ of patients with PUD $[17,18]$.

In addition, most patients with a perforated peptic ulcer are elderly with considerable comorbidity[19], among those patients a higher mortality rate (up to $25 \%$ ) and a morbidity rate of up to $50 \%$ have been reported, even in recent studies[20-22]. In particular, for patient $\geq 60$ years, the incidence increased over 10 -fold, and mortality more than 50 -fold, compared to younger ages [17, 23]. Overall prevalence of perforation is about $5 \%$ with mortality ranging from $8.5 \%$ to $25 \%[9,24]$.

Consequently, perforated peptic ulcer remains a frequent challenge to surgeons and optimal treatment strategies are needed.

The aim of this study is to analyze the post-operative outcomes of our series from a single center comparing open and laparoscopic repair.

\section{Methods:}

\section{Study design}

The present study was designed as a retrospective cohort evaluation. All data, patient demographics and outcomes were identified from a prospectively maintained database established at "St. Orsola Hospital - Emergency Surgery Unit - University of Bologna". Data were collected between May 2014 to December 2019 and included 109 patients with diagnosis of PUD. The diagnostic criteria were as follows: (1) pneumoperitoneum detected by abdominal x-ray and/ or abdominal computed tomography performed at the Emergency Room, and/or (2) gastric or duodenal ulcer confirmed by the endoscopy before the initial treatment or during the emergency surgical procedure. Preoperative endoscopy or intraoperative frozen sectioning was not routinely performed because of the emergency setting. Patients who underwent gastrectomy were excluded from the study, enrolling only those who underwent laparoscopic and open repairs. Overall, 94 patients were enrolled.

A retrospective analysis of preoperative, operative, and postoperative data was performed. Collected data included patient's demographics, clinical characteristics, operative details, and post-operative outcomes. Patients were divided into two groups to investigate the effect of the surgical approach: 53 patients in the laparoscopic group (LG), 41 patients in the open group (OG).

\section{Data collection}

Details of age, sex, history of PUD, ulcerogenic drugs (including non-steroidal anti-inflammatory drugs NSAIDs, systemic steroids, and low-dose aspirin) taken within 2 weeks before presentation, comorbidities (including cardiopulmonary disease, diabetes mellitus, and renal insufficiency) requiring treatment, American Society of Anesthesiologists (ASA) classification, were recorded. For each patient, the Boey score was retrospectively calculated for assessing the postoperative risks[25]. The score is calculated based on 3 factors: the presence of major medical illness, shock at the time of admission, estimated onset of perforation $>24 \mathrm{~h}$. Of note, in the original paper of this score, level 3 had a 100\% mortality.

Post-operative complications and 30-days postoperative outcomes were recorded prospectively. Followup was based on inpatient and outpatient data. Postoperative complications were classified according to the Dindo-Clavien classification[26]. According to the aforementioned classification, Grade I includes minor complications that do not require any intervention and that can be treated with routine medications like antipyretics, analgesics, diuretics, or physiotherapy; Grade II includes conditions that require major pharmacological intervention, like respiratory infections, ascites, blood transfusions, and asymptomatic pulmonary embolism; Grade III includes any complication requiring a surgical, endoscopic, or radiological intervention, like a respiratory infection requiring bronchoscopy, a pleural effusion requiring drainage, ascites or an abdominal collection requiring percutaneous drainage, and reoperation for abdominal collection, bleeding, or other reasons; Grade IV includes patients with life-threatening complications requiring Intensive Care Unit; Grade V includes death in the postoperative period. 


\section{Statistical analysis}

Results are expressed as median (range) unless otherwise stated. Comparisons between categorical variables were determined using the chi-square or Fisher's exact test, as appropriate. Continuous variables were assessed with the Mann-Whitney U-test. Logistic backward regression was undertaken to determine factors independently associated with mortality, morbidity and discharge at home including all factors where the P-value was less than 0.05 on univariate analysis. A statistical software package (SPSS Version XX.0; IBM Co, Armonk, NY, USA) was used for the analysis, with $\mathrm{p}<0.05$ considered statistically significant.

\section{Results:}

Ninety-four patients met inclusion criteria. Preoperative characteristics, surgical procedures and postoperative outcomes of the patients included in this study are listed in Table 1, Table 2, Table 3.

\begin{tabular}{|c|c|c|c|c|}
\hline & $\begin{array}{l}\text { Overall } \\
(n=94)\end{array}$ & $\begin{array}{c}\text { Laparoscopic } \\
\text { Group } \\
(n=53)\end{array}$ & $\begin{array}{c}\text { Open Group } \\
\quad(n=41)\end{array}$ & p-Value \\
\hline Age (years)* & $61.1 \pm 20.3$ & $51.9 \pm 18.5$ & $72.8 \pm 15.5$ & $<0.01$ \\
\hline Age $>80$ years & $20(21 \%)$ & $3(6 \%)$ & $17(41 \%)$ & $<0.01$ \\
\hline Male Sex & $58(62 \%)$ & $35(66 \%)$ & $23(56 \%)$ & 0.39 \\
\hline BMI $\left(\mathrm{Kg} / \mathrm{m}^{\wedge} 2\right)^{*}$ & $24.3 \pm 4.9$ & $23.5 \pm 4.1$ & $25.8 \pm 5.6$ & 0.02 \\
\hline $\begin{array}{l}\text { ASA Class } \\
I-I I \\
I I I-I V\end{array}$ & $\begin{array}{l}41(44 \%) \\
53(56 \%)\end{array}$ & $\begin{array}{l}34(64 \%) \\
19(36 \%)\end{array}$ & $\begin{array}{c}7(17 \%) \\
34(83 \%)\end{array}$ & $<0.01$ \\
\hline $\begin{array}{l}\text { Comorbidity } \\
\text { Cardio-Vascular } \\
\text { Diabetes } \\
\text { COPD } \\
\text { CRF } \\
\text { Obesity } \\
\end{array}$ & $\begin{array}{c}62(66 \%) \\
39(41 \%) \\
8(9 \%) \\
7(7 \%) \\
4(4 \%) \\
6(6 \%)\end{array}$ & $\begin{array}{c}26(49 \%) \\
12(23 \%) \\
2(4 \%) \\
1(2 \%) \\
- \\
3(6 \%) \\
\end{array}$ & $\begin{array}{c}36(88 \%) \\
26(63 \%) \\
6(15 \%) \\
6(15 \%) \\
4(10 \%) \\
3(7 \%) \\
\end{array}$ & $\begin{array}{c}<\mathbf{0 . 0 1} \\
<\mathbf{0 . 0 1} \\
<\mathbf{0 . 0 1} \\
<\mathbf{0 . 0 1} \\
<\mathbf{0 . 0 1} \\
1.00\end{array}$ \\
\hline Previous Abdominal Surgery & $40(43 \%)$ & $20(38 \%)$ & $20(49 \%)$ & 0.30 \\
\hline Previous history of PUD & $6(6 \%)$ & $5(9 \%)$ & $1(2 \%)$ & 0.23 \\
\hline Alchool abuse & $10(11 \%)$ & $6(11 \%)$ & $4(10 \%)$ & 1.00 \\
\hline Cigarette smoking & $15(16 \%)$ & $8(15 \%)$ & $7(17 \%)$ & 1.00 \\
\hline Use of NSAIDs & $26(28 \%)$ & $11(21 \%)$ & $15(37 \%)$ & 0.11 \\
\hline $\begin{array}{l}\text { Symptoms } \\
\text { Pain in abdomen } \\
\text { Vomiting/Nausea } \\
\text { Hyporexia } \\
\text { Fever }\left(>38.0^{\circ}\right) \\
\text { Abdominal distention } \\
\text { Costipation } \\
\end{array}$ & $\begin{array}{c}68(72 \%) \\
24(26 \%) \\
8(9 \%) \\
2(2 \%) \\
17(18 \%) \\
17(18 \%)\end{array}$ & $\begin{array}{c}41(77 \%) \\
17(32 \%) \\
5(9 \%) \\
1(2 \%) \\
8(15 \%) \\
10(19 \%) \\
\end{array}$ & $\begin{array}{c}27(66 \%) \\
7(17 \%) \\
3(7 \%) \\
1(2 \%) \\
9(22 \%) \\
7(17 \%) \\
\end{array}$ & $\begin{array}{l}0.25 \\
0.16 \\
1.00 \\
1.00 \\
0.43 \\
1.00 \\
\end{array}$ \\
\hline $\begin{array}{l}\text { Laboratory Tests } \\
W B C\left(x 10^{\wedge} 9 / L\right) * \\
\text { Hemoglobin }(g r / d L) * \\
C R P(m g / d L) * \\
\text { Creatinine }(\text { microMol/L)* }\end{array}$ & $\begin{array}{c}14.70 \pm 7.76 \\
13.70 \pm 2.62 \\
5.34 \pm 8.48 \\
1.49 \pm 2.06 \\
\end{array}$ & $\begin{array}{c}14.35 \pm 6.10 \\
14.15 \pm 2.33 \\
4.15 \pm 8.31 \\
1.26 \pm 2.44 \\
\end{array}$ & $\begin{array}{c}15.12 \pm 9.44 \\
13.11 \pm 2.88 \\
7.06 \pm 8.57 \\
1.79 \pm 1.41 \\
\end{array}$ & $\begin{array}{l}0.63 \\
0.06 \\
0.10 \\
0.22 \\
\end{array}$ \\
\hline $\mathrm{CRP}>0.5(\mathrm{mg} / \mathrm{dL})$ & $62(66 \%)$ & $27(51 \%)$ & $35(85 \%)$ & $<0.01$ \\
\hline $\mathrm{WBC}>10\left(\times 10^{\wedge} 9 / \mathrm{L}\right)$ & $63(67 \%)$ & $37(70 \%)$ & $26(63 \%)$ & 0.66 \\
\hline $\begin{array}{c}\text { Boey Score } \\
0-1 \\
2-3 \\
\end{array}$ & $\begin{array}{l}66(70 \%) \\
28(30 \%) \\
\end{array}$ & $\begin{array}{c}43(81 \%) \\
8(19 \%)\end{array}$ & $\begin{array}{l}21(51 \%) \\
20(49 \%) \\
\end{array}$ & $<0.01$ \\
\hline $\begin{array}{l}\text { Radiological Imaging } \\
\text { RX Abdomen } \\
\text { TC scan } \\
\text { RX + TC } \\
\text { Endoscopy }\end{array}$ & $\begin{array}{c}41(44 \%) \\
11(12 \%) \\
39(41 \%) \\
3(3 \%)\end{array}$ & $\begin{array}{c}25(47 \%) \\
9(17 \%) \\
18(34 \%) \\
1(2 \%)\end{array}$ & $\begin{aligned} 16 & (39 \%) \\
2 & (5 \%) \\
21 & (51 \%) \\
2 & (5 \%)\end{aligned}$ & $\begin{array}{l}0.53 \\
0.11 \\
0.14 \\
0.58\end{array}$ \\
\hline
\end{tabular}

Table 1: Pre-operative characteristics of patients.

CRF: chronic renal failure; COPD: chronic obstructive pulmonary disease; CRP: c-reactive protein; WBC: white blood cell count. Values in parentheses are percentages unless indicated otherwise; *values are mean $\pm S D$. 


\begin{tabular}{|c|c|c|c|c|}
\hline & $\begin{array}{l}\text { Overall } \\
(n=94)\end{array}$ & $\begin{array}{c}\text { Laparoscopic } \\
\text { Group } \\
(n=53)\end{array}$ & $\begin{array}{l}\text { Open Group } \\
\quad(n=41)\end{array}$ & p-Value \\
\hline Surgical Procedure & & & & - \\
\hline Open & $41(44 \%)$ & - & $41(100 \%)$ & \\
\hline Laparoscopic & $53(56 \%)$ & $53(100 \%)$ & - & \\
\hline Conversion to Open & - & $12(22 \%)$ & - & \\
\hline Intra-operative Endoscopy & $10(11 \%)$ & $4(8 \%)$ & $6(15 \%)$ & 0.32 \\
\hline First flatus (days)* & $4.01 \pm 1.49$ & $3.46 \pm 1.54$ & $4.79 \pm 1.55$ & $<0.01$ \\
\hline NG tube removal (days)* & $4.48 \pm 3.72$ & $2.31 \pm 1.19$ & $4.09 \pm 2.30$ & $<0.01$ \\
\hline Re-Feeding (days)* & $3.04 \pm 1.93$ & $3.46 \pm 1.17$ & $5.97 \pm 5.22$ & $<0.01$ \\
\hline $\begin{array}{l}\text { Surgical drainage removal } \\
\text { (days)* }\end{array}$ & $5.28 \pm 3.94$ & $4.40 \pm 1.22$ & $6.59 \pm 5.85$ & $<0.01$ \\
\hline Duration of Procedure (min)* & $92.93 \pm 34.37$ & $93.33 \pm 31.54$ & $92.46 \pm 37.87$ & 0.90 \\
\hline Duration of Procedure (>90min) & $36(38 \%)$ & $19(38 \%)$ & $17(41 \%)$ & 0.67 \\
\hline
\end{tabular}

Table 2: Surgical and peri-operative characteristics of population.

NG: nasogastric. Values in parentheses are percentages unless indicated otherwise; *values are mean $\pm S D$.

\begin{tabular}{|c|c|c|c|c|}
\hline & $\begin{array}{l}\text { Overall } \\
(n=94)\end{array}$ & $\begin{array}{c}\text { Laparoscopic } \\
\text { Group } \\
(n=53) \\
\end{array}$ & $\begin{array}{c}\text { Open Group } \\
(n=41)\end{array}$ & p-Value \\
\hline Death in Hospital & $18(19 \%)$ & $2(4 \%)$ & $16(39 \%)$ & $<0.01$ \\
\hline 30-day Mortality & $18(19 \%)$ & $2(4 \%)$ & $16(39 \%)$ & $<0.01$ \\
\hline $\begin{array}{l}\text { Complication } \\
\text { (Clavien-Dindo) }\end{array}$ & $19(20 \%)$ & $10(19 \%)$ & $9(22 \%)$ & 0.80 \\
\hline $\begin{array}{l}\text { Grade I-II } \\
\text { Grade III-IV }\end{array}$ & $\begin{array}{c}15(16 \%) \\
4(4 \%)\end{array}$ & $\begin{array}{c}8(15 \%) \\
2(4 \%)\end{array}$ & $\begin{array}{l}7(17 \%) \\
2(5 \%)\end{array}$ & 1.00 \\
\hline Re-Operation & $5(5 \%)$ & $1(2 \%)$ & $4(10 \%)$ & 0.16 \\
\hline Hospital Stay (days)* & $9.49 \pm 8.72$ & $6.51 \pm 3.37$ & $13.20 \pm 11.55$ & $<0.01$ \\
\hline Discharge at Home & $73(78 \%)$ & $49(92 \%)$ & $24(59 \%)$ & $<0.01$ \\
\hline
\end{tabular}

Table 3: Postoperative outcomes.

Values in parentheses are percentages unless indicated otherwise; *values are mean $\pm S D$.

Unadjusted Model

No. of patients Odds ratio [CI 95\%] P-value

Adjusted for co-variables

\begin{tabular}{|c|c|c|c|c|c|}
\hline & \multirow[b]{2}{*}{ No. of patients } & & \multirow[b]{2}{*}{ Odds ratio [CI 95\%] } & \multirow[b]{2}{*}{ P-value } \\
\hline & & Odds ratio [CI 95\%] & P-value & & \\
\hline \multicolumn{6}{|l|}{ Complications } \\
\hline Laparoscopic Group & $10(19 \%)$ & 1.00 & - & 1.00 & - \\
\hline Open Group & $9(22 \%)$ & 2.309 [0.791-6.737] & 0.126 & $1-952[0.551-6.916]$ & 0.300 \\
\hline \multicolumn{6}{|l|}{ In-Hospital Mortality } \\
\hline Laparoscopic Group & $2(4 \%)$ & 1.00 & - & 1.00 & - \\
\hline Open Group & $16(39 \%)$ & $21.649[1.212-386.817]$ & 0.037 & $17.211[0.120-2478.11]$ & 0.262 \\
\hline \multicolumn{6}{|l|}{ Discharge at Home } \\
\hline Laparoscopic Group & $49(92 \%)$ & 1.00 & - & 1.00 & - \\
\hline Open Group & $24(59 \%)$ & $1.058[0.087-12.856]$ & 0.965 & $2.467[0.023-261.013]$ & 0.704 \\
\hline
\end{tabular}

Table 4: Logistic regression model exploring the relationship between two group and complications, in-hospital mortality and 30day mortality.

The adjusted model accounts for the possible impact of the co-variables: age <80 years, Boey Score 2-3, presence of cardio-vascular disease, presence of CRF, presence of COPD, presence of Diabetes, ASA score 3 or 4 . Laparoscopic procedure and grade of cholecystitis. Patients of Laparoscopic Group represented the reference group. 


\section{Clinical data}

The average age of two groups ranged from 51.9 years in LG to 72.8 years in OG $(\mathrm{p}<0.01)$. When comparing two groups, the gender distribution was not significantly different $(p=0.39)$, male patient was more frequent in LG with $66 \%$ percentage.

The overall comorbidity rate differed significantly between the two groups $(\mathrm{p}<0.01)$ : in particular the distribution of cardio-vascular risk factor, diabetes, chronic renal failure (CRF) and chronic obstructive pulmonary disease were more frequent in OG. Not surprisingly, ASA classification differed significantly $(\mathrm{p}<0.01)$ between the groups.

The two groups did not present significant differences in terms of previous abdominal surgery, history of previous peptic ulcer disease, cigarette smoking, abuse of Alcohol and use of non-steroidal anti-inflammatory drugs (NSAIDs) ( $p=\mathrm{NS})$.

Blood tests and radiological investigation were performed at the admission in Emergency Department in every patient, and were summarized in Table 1 .

Seventy-eight percent of patient had clinical signs of peritonitis at presentation. The abdomen $x$-ray depicted free air in abdomen in 41 patients (44\%), a CT scan after a negative radiography was required in 39 patients. In 3 patients the diagnosis of PUD was made during an endoscopy performed on suspicion of gastrointestinal bleeding.

\section{Intraoperative and perioperative data}

The overall median operative time was 92.9 34.4 [35-255] minutes, no significant difference was shown between the two groups $(p=0.90)$. In all cases warm saline was used for intraoperative peritoneal lavage until clear fluid was obtained and the overall average amount of it was $1798.8 \pm 1213.9 \mathrm{ml}$.

The reintroduction of oral diet varied across the groups and was dependent on the first bowel movement and the severity of peritonitis. The naso-gastric tube and surgical drainage were removed earlier in the LG than OG with statistically significant differences $(p<0.01)$.

\section{Postoperative data}

Eighteen patients (19.1\%) died in hospital after surgery: 2 in LG and 16 in OG, respectively $(p=<0.01)$. In particular, 15 patients had a Boey score 2 and one patient had a Boey score 3. Among these patients, in two cases the death occurred after a re-operation; in one patient due to a gastric suture leakage, in the other one due to an evisceration.

Post-operative complications occurred in 19 patients $(20 \%)$ of our study cohort. In particular, mild complications (Clavien grade I-II) were more prevalent than severe complications (Clavien grade III-IV). However, no significant differences were recorded between the two groups. Five patients had a reoperation. In two patients the reoperation was due to a gastric suture leakage, in the remaining three cases due to an evisceration.

The overall median hospital stay was 9.49 \pm 8.72 [160] days and was significantly affected by surgical procedure; not surprisingly the median hospital stay was longer in OG compared to LG, with a difference of about 7 days $(\mathrm{p}<0.01)$.

The impact of laparoscopic procedure on the overall occurrence of complications, postoperative death and discharge at home in relation to other variables considered in the logistic regression model is shown in Table 4.

Mortality showed to be more favourable in LG in the unadjusted model. However, after adjusting for covariables, this difference was not found to be statistically significant.

\section{Discussion:}

The first recorded description of a peptic ulcer perforation was by the Princess Anne Henriette of England, the daughter of King Charles I of England and Princess Marie Henriette of France[27].

Since that description, peptic perforation was a serious complication of PUD affected by worse outcome. The overall mortality due to perforation peritonitis ranges between $6 \%$ and $27 \%$. One of the most important factors responsible for mortality is septicemia[28].

Perforated peptic ulcer can mimic acute cholecystitis, acute pancreatitis, or appendicitis when gastroduodenal contents spread out causing pain in abdomen[29].

The perforation leads to chemical peritonitis, with or without contamination with micro-organisms. Spillage of gastroduodenal contents is usually diffuse but may be localized in the upper abdomen. After 6 to 12 hours many patients may obtain some spontaneous relief of the pain due to dilution of the irritating gastroduodenal contents by the ensuing peritoneal exudate. The intraabdominal infection appears after 12 to 24 hours[30].

Definitive surgical procedures have been routinely performed for decades in Japan, other Asian countries, and Eastern Europe; nowadays, non-definitive surgical procedures like simple closure with or without omentoplasty and drainage are the most popular in case of perforation[31].

Notwithstanding aggressive surgical procedures such as gastric disconnection, antrectomy, gastrostomy, lateral duodenostomy and feeding jejunostomy with restoration of intestinal continuity were described in literature; nowadays the surgical options are suture of the perforation with or without omentoplasty[32].

However, it is controversial whether laparoscopic approach or conventional open surgery should be chosen.

In literature, negative factors for the laparoscopic approach are shock at the diagnosis, delayed presentation (> $24 \mathrm{~h})$, confounding medical conditions, age $>70$ years, ASA (American Society of Anesthesiologists) score 3-4 and Boey score of $\geq 2$, ulcer location or large perforation size (> 6-10 mm). The most accepted but discussed contraindication is signs of shock due to the negative impact of increase duration of surgery and negative influence of pneumoperitoneum on renal function[33]. For the laparoscopic approach the concern is the $\mathrm{CO} 2$ pneumoperitoneum who leads to increased intra-abdominal pressure intraoperatively: it is related to growing risk of bacteremia and sepsis due to the increased chance of bacterial translocation from peritoneal cavity into the bloodstream, increasing the occurrence of pneumonia in patients selected for this 
approach[34].

In our cohort of patients, the OG presented more fragile patients with more severe ASA score and a greater number of Boey 2-3 than the LG.

The most common cause of conversion to open surgery was an inability to repair the ulcer due to either technical difficulties or size of perforation. The conversion rates are directly influenced by the laparoscopic skills and experience of the surgeon. In the literature it ranges between $2.6 \%$ to $7.7 \%$ [35].

Overall complications rate in our series was $20 \%$ which is comparable to other reports[36, 37].

A recent study by Teoh et al.[38] found that a laparoscopic approach in high-risk patients was not associated with increased morbidity and mortality when compared to an open approach, particularly if the ASA grading was below 3 .

A Cochrane meta-analysis[32] showed a trend in reducing intra-abdominal septic complications, wound infections, postoperative ileus, pulmonary complications, and mortality with laparoscopy.

A previous meta-analysis by Lau[39] showed a lower incidence of post-operative complications in the laparoscopic group but even a higher rate of reoperation. In our cohort of patients, there were 5 reoperations in the 2 groups. One patient in the LG and 4 patients in the OG, respectively $(\mathrm{p}=0.16)$.

The main limitation of the present study is the relatively low sample of patients. However, all our data were prospectively collected, and all surgical procedures were performed by the same group of surgeons.

\section{Conclusion:}

Gastric perforation is a severe complication of PUD. Early diagnosis and surgical treatment are mandatory to avoid peritonitis progression with consequent high mortality risk. Laparoscopy is a valid alternative to open surgery in selected patients and in centers with experience in minimally invasive surgery.

\section{Acknowledgements}

None.

\section{Contributors}

$\mathrm{SV}, \mathrm{VDA}, \mathrm{AL}, \mathrm{MC}, \mathrm{VT}$ conceptualized and designed the study, acquired, and analyzed data, interpreted the study results, drafted the manuscript, and critically revised the manuscript for important intellectual content. RDI, EG, acquired, and analyzed data, interpreted the study results.

\section{Funding}

No funding was received for this study.

\section{Competing interests}

No benefits in any form have been received or will be received from a commercial party related directly or indirectly to the subject of this article.

\section{Availability of data and materials}

Further information is available from the corresponding author on reasonable request.

\section{Ethics approval}

all procedures performed by the participants of our study were in accordance with the ethical standards of the institutional and/or national research committee and with the 1964 Helsinki declaration and its later amendments or comparable ethical standards. The study received approval from the hospital's institutional review board (156/2018/Oss/AOUBo, 18/04/18).

\section{Provenance and peer review}

Not commissioned; externally peer reviewed.

\section{Open access}

This is an Open Access article distributed in accordance with the Creative Commons Attribution NonCommercial (CC BY-NC 4.0) license, which permits others to distribute, remix, adapt, build upon this work noncommercially, and license their derivative works on different terms, provided

the original work is properly cited and the use is non-commercial. See: http://creativecommons.org/ licenses/by-nc/4.0/

\section{References}

[1] Bae S, Shim KN, Kim N, Kang JM, Kim DS, Kim KM, et al. Incidence and short-term mortality from perforated peptic ulcer in Korea: a population-based study. J Epidemiol. 2012;22:508-16.

[2] Hermansson M, Ekedahl A, Ranstam J, Zilling T. Decreasing incidence of peptic ulcer complications after the introduction of the proton pump inhibitors, a study of the Swedish population from 19742002. BMC Gastroenterol. 2009;9:25.

[3] Lassen A, Hallas J, Schaffalitzky de Muckadell OB. Complicated and uncomplicated peptic ulcers in a Danish county 1993-2002: a population-based cohort study. Am J Gastroenterol. 2006;101:945-53.

[4] Svanes C. Trends in perforated peptic ulcer: incidence, etiology, treatment, and prognosis. World J Surg. 2000;24:277-83.

[5] Bertleff MJ, Lange JF. Perforated peptic ulcer disease: a review of history and treatment. Dig Surg. 2010;27:161-9.

[6] Wang YR, Richter JE, Dempsey DT. Trends and outcomes of hospitalizations for peptic ulcer disease in the United States, 1993 to 2006. Ann Surg. 2010;251:51-8.

[7] Soreide K, Sarr MG, Soreide JA. Pyloroplasty for benign gastric outlet obstruction--indications and techniques. Scand J Surg. 2006;95:11-6.

[8] Dongo AE, Uhunmwagho O, Kesieme EB, Eluehike SU, Alufohai EF. A Five-Year Review of Perforated Peptic Ulcer Disease in Irrua, Nigeria. Int Sch Res Notices. 2017;2017:8375398.

[9] Thorsen K, Soreide JA, Kvaloy JT, Glomsaker T, Soreide K. Epidemiology of perforated peptic ulcer: age- and gender-adjusted analysis of incidence and mortality. World J Gastroenterol. 2013;19:34754.

[10] Hodnett RM, Gonzalez F, Lee WC, Nance FC, Deboisblanc R. The need for definitive therapy in the management of perforated gastric ulcers. Review of 202 cases. Ann Surg. 1989;209:36-9.

[11] Horowitz J, Kukora JS, Ritchie WP, Jr. All perforated ulcers are not alike. Ann Surg. 1989;209:693-6; discussion 6-7.

[12] Lanng C, Palnaes Hansen C, Christensen A, Thagaard CS, Lassen M, Klaerke A, et al. Perforated gastric ulcer. Br J Surg. 1988;75:758-9.

[13] Ergul E, Gozetlik EO. Emergency spontaneous gastric perforations: ulcus versus cancer. Langenbecks Arch Surg. 2009;394:643-6.

[14] Muller MK, Wrann S, Widmer I, Klasen J, Weber M, Hahnloser D. Perforated Peptic Ulcer Repair: Factors Predicting Conversion in Laparoscopy and Postoperative Septic Complications. World J Surg. 2016;40:2186-93

[15] Chung KT, Shelat VG. Perforated peptic ulcer - an update. World J Gastrointest Surg. 2017;9:1-12.

[16] Schulte-Hermes M, Klein-Wiele O, Vorpahl M, Seyfarth M. Acute tension pneumopericardium due to perforated gastric ulcer without diagnostic radiographic findings $72 \mathrm{~h}$ before perforation. J Cardiol Cases. 2018;18:201-3.

[17] Bhattacharjee HK, Misra MC, Kumar S, Bansal VK. Duodenal perforation following blunt abdominal trauma. J Emerg Trauma Shock. 2011;4:514-7.

[18] Milosavljevic T, Kostic-Milosavljevic M, Jovanovic I, Krstic M. Complications of peptic ulcer disease. Dig Dis. 2011;29:491-3.

[19] Sarosi GA, Jr., Jaiswal KR, Nwariaku FE, Asolati M, Fleming JB, 
Anthony T. Surgical therapy of peptic ulcers in the 21st century: more common than you think. Am J Surg. 2005;190:775-9.

[20] Moller MH, Adamsen S, Thomsen RW, Moller AM, Peptic Ulcer Perforation trial g. Multicentre trial of a perioperative protocol to reduce mortality in patients with peptic ulcer perforation. Br J Surg. 2011;98:802-10

[21] Nakano A, Bendix J, Adamsen S, Buck D, Mainz J, Bartels P, et al. 30-days mortality in patients with perforated peptic ulcer: A national audit. Risk Manag Healthc Policy. 2008;1:31-8.

[22] Towfigh S, Chandler C, Hines OJ, McFadden DW. Outcomes from peptic ulcer surgery have not benefited from advances in medical therapy. Am Surg. 2002;68:385-9.

[23] Lee CW, Sarosi GA, Jr. Emergency ulcer surgery. Surg Clin North Am. 2011;91:1001-13.

[24] Byrge N, Barton RG, Enniss TM, Nirula R. Laparoscopic versus open repair of perforated gastroduodenal ulcer: a National Surgical Quality Improvement Program analysis. Am J Surg. 2013;206:957-62; discussion 62-3.

[25] Boey J, Choi SK, Poon A, Alagaratnam TT. Risk stratification in perforated duodenal ulcers. A prospective validation of predictive factors. Ann Surg. 1987;205:22-6.

[26] Dindo D, Demartines N, Clavien PA. Classification of surgical complications: a new proposal with evaluation in a cohort of 6336 patients and results of a survey. Ann Surg. 2004;240:205-13.

[27] Baron JH. Paintress, princess and physician's paramour: poison or perforation? J R Soc Med. 1998;91:213-6.

[28] Gupta S, Kaushik R, Sharma R, Attri A. The management of large perforations of duodenal ulcers. BMC Surg. 2005;5:15.

[29] Bali RS, Verma S, Agarwal PN, Singh R, Talwar N. Perforation peritonitis and the developing world. ISRN Surg. 2014;2014:105492.

[30] Kutlu OC, Garcia S, DissanaikeS. The successful use of simple tube duodenostomy in large duodenal perforations from varied etiologies. Int J Surg Case Rep. 2013;4:279-82.

[31] Gurusamy KS, Pallari E. Medical versus surgical treatment for refractory or recurrent peptic ulcer. Cochrane Database Syst Rev. 2016;3:CD011523

[32] Sanabria A, Villegas MI, Morales Uribe CH. Laparoscopic repair for perforated peptic ulcer disease. Cochrane Database Syst Rev. 2013:CD004778.

[33] Camera L, Calabrese M, Romeo V, Scordino F, Mainenti PP, Clemente $\mathrm{M}$, et al. Perforated duodenal ulcer presenting with a subphrenic abscess revealed by plain abdominal X-ray films and confirmed by multi-detector computed tomography: a case report. J Med Case Rep. 2013;7:257.

[34] Pohl D, Schmutz G, Plitzko G, Kroll D, Nett P, Borbely Y. Perforated duodenal ulcers after Roux-Y Gastric Bypass. Am J Emerg Med. 2018;36:1525 e1- e3.

[35] Tan S, Wu G, Zhuang Q, Xi Q, Meng Q, Jiang Y, et al. Laparoscopic versus open repair for perforated peptic ulcer: A meta analysis of randomized controlled trials. Int J Surg. 2016;33 Pt A:124-32.

[36] Khan SH, Aziz SH, Ul-Haq MI. Perforated peptic ulcer: a review of 36 cases. Professional Med J. 2011:124-7.

[37] Lee FY, Leung KL, Lai BS, Ng SS, Dexter S, Lau WY. Predicting mortality and morbidity of patients operated on for perforated peptic ulcers. Arch Surg. 2001;136:90-4.

[38] Teoh AY, Chiu PW, Kok AS, Wong SK, Ng EK. The selective use of laparoscopic repair is safe in high-risk patients suffering from perforated peptic ulcer. World J Surg. 2015;39:740-5.

[39] Lau H. Laparoscopic repair of perforated peptic ulcer: a metaanalysis. Surg Endosc. 2004;18:1013-21. 